\title{
Fruit-Eating in Management of Hypertension
}

\author{
R. S. Rakhi Menon
}

\begin{abstract}
Hypertension has become a major concern among people. High blood pressure can lead to heart diseases, strokes, kidney failure and cognitive decline. Adding edible fruits to the diet may be helpful in decreasing high blood pressure. This review focuses on the role of edible fruits like watermelon, durian, black berries, Figs and dragon fruit in the management of hypertension.
\end{abstract}

Keywords: Figs, Dragon fruit, watermelon, Cyclanthera pedata, banana, tomato, Schizandra

\section{Introduction}

A blood pressure level of 120/80 $\mathrm{mm}$ of $\mathrm{Hg}$, is considered as normal. If one is suffering from high blood pressure, then it is imperative to work with your health care provider, to understand the ways it can be controlled or lowered. Most medical practitioner's advice a combination of medications and lifestyle changes, in order to successfully combat high blood pressure.

Lifestyle changes include modification in diet and a proper exercise regimen. It has been scientifically proven that a diet that includes lots of fruits and vegetables, can help in lowering blood pressure naturally.

\section{Edible Fruits and Hypertension}

\section{Figs}

Figs grow on the Fichus tree (Ficus carica), which is a member of the Mulberry family. They are unique in that they have an opening, called the "ostiole" or "eye," which is not connected to the tree, but which helps the fruit's development by increasing its communication with the environment. Figs range dramatically in color and subtly in texture depending upon the variety. Figs are a good source of potassium, a mineral that helps to control blood pressure. Since many people not only do not eat enough fruits and vegetables, but do consume high amounts of sodium as salt is frequently added to processed foods, they may be deficient in potassium. Low intake of potassium-rich foods, especially when coupled with a high intake of sodium, can lead to hypertension. In the Dietary Approaches to Stop Hypertension (DASH) study, one group ate servings of fruits and vegetables in place of snacks and sweets, and also ate low-fat dairy food. This diet delivered more potassium, magnesium and calcium. Another group ate a "usual" diet low in fruits and vegetables with a fat content like that found in the average American Diet.(1)After eight weeks, the group that ate the enhanced diet lowered their blood pressure by an average of 5.5 points (systolic) over 3.0 points (diastolic)

\section{Dragon Fruit}

Dragon fruit is also rich in phytoalbumins which are highly valued for their antioxidant properties. Dragon fruit or Hylocereus polyrhizus is rich in fibers, vitamin C, minerals and phytoalbumins which are highly valued for their antioxidant properties. The dragon fruit helps the digestive process, prevent colon cancer and diabetes, neutralize toxic substances such as heavy metal, reduce cholesterol levels and high blood pressure and consumed regularly the dragon fruit can help against asthma and cough.(2) It is also rich with potassium, protein, fiber, sodium and calcium which goods for health than other fruits

\section{Watermelon}

Watermelon (citrullus lanatus) is a great source of potassium, and extremely low in sodium. Natural sources of potassium help the heart and is beneficial for patients with high blood pressure. Watermelon with red flesh is a significant source of lycopene. Researchers recommend to increase the lycopene and beta-carotene your watermelon delivers by storing it at room temperature (3).

\section{Cyclanthera Pedata}

Achocha is a vigorous climber producing small edible fruits. Achocha is a slow starter, but when the summer gets warmer, it suddenly takes off with a surprising vitality. It's divided foliage and delicate flowers make it a valuable ornamental. The yield from one single plant is hundreds of delicious tender fruits.Caigua products have been gaining in popularity and availability in the U.S. natural products market over the last several years. Most are marketing these supplements as a cholesterol management aid, for hypertension, and blood-sugar regulation. Most of the available products in the United States are tablets or capsules of the dried or freeze-dried fruit juice (4)

\section{Banana}

+ Potassium-rich food such as bananas could play a role in controlling blood pressure.

+ Bananas are rich in potassium and have a high fiber content.

+ Bananas are free of cholesterol, sodium and fat. According to scientists, two bananas a day can help control high blood pressure, offering a cheap alternative to expensive drugs. Researchers in India have reported that blood pressure fell by $10 \%$ in people who ate two bananas daily for a week (5).

\section{Tomato}

Tomatoes are rich in calcium and potassium, and contain vitamins $\mathrm{A}, \mathrm{C}, \mathrm{E}$, and are naturally low in calories. Tomato varieties are available with double the normal vitamin $\mathrm{C}$ (Double rich), 40 times normal vitamin A (97L97), high levels of anthocyanin (P20 Blue), and two to four times the normal amount of lycopene (numerous available cultivars with the high crimson gene)(6).Tomato extract helps reduce blood pressure. Tomatoes are high in gamma-amino butyric acid (GABA), a compound that can help lower blood pressure 


\section{International Journal of Science and Research (IJSR) \\ ISSN (Online): 2319-7064}

Index Copernicus Value (2015): 78.96 | Impact Factor (2015): 6.391

\section{Schizandra}

Schizandra is a dried fruit used in alternative or complementary medicine for a wide variety of purposes. Although studies in China have supported the use of schizandra in therapy for viral hepatitis, the claimed benefits for blood pressure seem to have gone largely unstudied. Nevertheless, they are widely reported in the herbal and alternative medicine literature. Many guides to alternative and complementary medicine report that schizandra can be used to reduce blood pressure (7).

\section{Conclusion}

It suggests that adding edible fruits like watermelon, banana, tomato, schizandra, figs, and dragon fruit to the diet will be helpful in the prevention of hypertension. Our results suggests that it is the best alternative for hypertensive drugs in the natural way.

\section{References}

[1] Appel LJ, Moore TJ, Obarzanek E, et al. A clinical trial of the effects of dietary patterns on blood pressure. DASH Collaborative Research Group. N Eng. J Med. 1997 Apr 17; 336(16):1117-24. 1997.

[2] Canal JR, Torres MD, Romero A, Perez C. A chloroform extract obtained from a decoction of Ficus carica leaves improves the cholesterolaemic status of rats with streptozotocin- induced diabetes. Acta Physiol Hung 2000; 87(1):71-6. 2000. PMID: 13400.

[3] Cho E, Seddon JM, Rosner B, Willett WC, Hankinson SE. Prospective study of intake of fruits, vegetables, vitamins, and carotenoids and risk of age-related maculopathy. Arch Ophthalmol. 2004 Jun; 122(6):88392. 2004. PMID: 15197064.

[4] de Amorin A, Borba HR, Carauta JP, et al. Anthelmintic activity of the latex of Ficus species. J Ethnopharmacol 1999 Mar; 64(3):255-8. 1999. PMID: 13410.

[5] Ensminger AH, Esminger M. K. J. e. al. Food for Health: A Nutrition Encyclopedia. Clovis, California: Pegus Press; 1986. 1986. PMID: 15210.

[6] Popenoe. H. et al Lost Crops of the Incas National Academy Press 1990 ISBN 0-309-04264-X An excellent book. Very readable, with lots of information and good pictures of some lesser known food plants of S. America.

[7] Wood, Rebecca. The Whole Foods Encyclopedia. New York, NY: Prentice-Hall Press; 1988. 1988. PMID: 15220 